\title{
A simple approach to synthesize novel sulfur/graphene oxide/multiwalled carbon nanotube composite cathode for high performance lithium/sulfur batteries
}

\author{
Guanghui Yuan $^{1} \cdot$ Yan Zhao $^{2} \cdot$ Huafeng Jin $^{1} \cdot$ Zhumabay Bakenov $^{3}$
}

Received: 19 January 2016 /Revised: 14 April 2016/Accepted: 30 April 2016

(C) Springer-Verlag Berlin Heidelberg 2016

\begin{abstract}
A sulfur/graphene oxide/multiwalled carbon nanotube (S/GO/MWNT) composite was synthesized via a simple ultrasonic mixing method followed by heat treatment. By taking advantage of this solution-based self-assembly synthesis route, poisonous and noxious reagents and complicated fabrication processes are rendered unnecessary, thereby simplifying its manufacturing and decreasing the cost of the final product. Transmission and scanning electronic microscopy observations indicated the formation of the threedimensional interconnected S/GO/MWNT composite through the environmentally friendly process. The GO layers and long MWNTs synergistically constructed hierarchical electron/ion pathways, favoring the ion transport and electrolyte diffusion. The interlaced network can serve as sponges to physically absorb polysulfides to their wrinkled surface and porous structure. In addition, GO could confine the polysulfides' dissolution through chemical absorption by the functional groups on GO layers. Therefore, the resulting S/GO/MWNT composite exhibits good rate capability and highly stable specific discharge capacity of $773 \mathrm{~mA} \mathrm{~h} \mathrm{~g}^{-1}$ after 100 cycles at $0.1 \mathrm{C}$.
\end{abstract}

\footnotetext{
Guanghui Yuan

chem_yuan@163.com

Yan Zhao

285760410@qq.com
}

1 College of Chemistry and Chemical Engineering, Ankang University, Shaanxi, Ankang 725000, China

2 Research Institute for Energy Equipment Materials, Hebei University of Technology, Tianjin 300130, China

3 Institute of Batteries LLC, PI Nazarbayev University Research and Innovation System, Nazarbayev University, 53 Kabanbay Batyr Avenue, Astana, Kazakhstan 010000
Keywords Lithium/sulfur battery · Sulfur/graphene oxide/ multiwalled carbon nanotube composite - Ultrasonic mixing · Electrochemical performance

\section{Introduction}

The rapidly growing needs in advanced high performance energy storage systems for the emerging largescale applications, including hybrid electric vehicles and electric vehicles, offer tremendous opportunities for researchers to develop next-generation high performance rechargeable batteries [1]. For this, sulfur stands as an ideal cathode material due to its theoretical specific capacity of $1672 \mathrm{~mA} \mathrm{~h} \mathrm{~g}^{-1}$, based on the complete reaction of sulfur with lithium metal to form $\mathrm{Li}_{2} \mathrm{~S}$ [2]. In addition, sulfur is abundant, low cost, and environmentally friendly [3]. Despite these advantages, sulfur confronts several problems, such as the intrinsic poor electronic conductivity of sulfur and high solubility of the intermediate products of its electrochemical reaction with lithium, the polysulfides, in liquid organic electrolytes, which causes rapid capacity loss upon repeated cycling and restricts practical application of Li-S batteries [4]. To overcome these critical issues, there have been tremendous efforts to find a host material, which would improve the electrical conductivity of the sulfur cathode and trap the soluble polysulfide intermediates [5-9]. For example, micro-/mesoporous carbon, carbon nanotubes, or graphene are considered as very promising conductive frameworks to composite with sulfur to form a desired structure for superior performance [10-13]. 
Recently, some studies have been focused on the synthesis of graphene/sulfur hybrids for Li-S batteries using various methods. Nevertheless, as a twodimensional conductive support, graphene material has low conductive ability between the graphene sheets, which causes low electrochemical accessibility and might limit the rate capability of the sulfur-based composite cathodes [14]. To solve this problem, intercalating carbon nanotubes between graphene sheets and linking graphene, forming a conductive network, could improve the three-dimensional conductivity of graphene sheets and meanwhile supply an unimpeded and continuous path for electron and $\mathrm{Li}$ ion transfer and accommodate the volume variation of sulfur during charge/discharge cycling $[15,16]$. In Zhang's study, a novel graphene/single-walled carbon nanotube hybrid was designed by one-step catalytic growth. This hybrid can obviously restrain the polysulfide anion diffusion phenomenon and improve the electrochemical performance of Li-S battery [17]. Moreover, a sulfur-carbon nanotube/graphene nanocomposite was fabricated as a binder-free sulfur cathode. The carbon nanotube/graphene framework enables better dispersion of sulfur and allows each sulfur particle to closely attach to the conductive components, which greatly enhance the electronic conductivity and thereby approach the full potential of the active materials [18]. Despite the graphene/sulfur or graphene/carbon nanotube/sulfur composites that can show good electrochemical performance, the complicated preparation of pristine graphene makes the reported synthesis methods, typically as a multi-step approach, usually complicated and challenging for large-scale application. Besides, the carbon materials such as micro-/mesoporous carbon, carbon nanotubes, and graphene are non-polar. The interactions between the non-polar carbon hosts and the polar polysulfides are weak physical absorptions, which makes this strategy less effective in entrapping polar polysulfides. Therefore, it is of great urgency and important to develop new and efficient sulfur-based hybrids through a simple and environmentally friendly process [19].

Polar materials are thought to form relatively strong chemical bonds with lithium polysulfides, thus effectively keeping them within the cathode [20]. Recently, many works are focused on introducing polar materials like metal oxides [21-23] into the sulfur electrode to form strong chemical binding with polysulfides, resulting in considerable gains in coulombic efficiency and cycling stability. Graphene oxide (GO), regarded as a functional graphene bearing oxygen functional groups on its basal planes and edges, has attracted much interest to prepare the composite cathodes for Li-S batteries [24-27]. Comparing to the non-polar graphene, GO shows strong polarity, and it is found that the functional groups on GO surface can act as immobilizers and effectively confine polysulfides from dissolving [24]. Furthermore, GO, as an intermediate during graphene synthesis by oxidationexfoliation-reduction of graphite, possesses other advantages such as lower cost and shorter possessing time compared with graphene [14]. Unfortunately, GO is a little poor in electronic conductivity, which may lead to undesirable compromises in specific capacity and rate performance. Therefore, it is still a great challenge to effectively restrict lithium polysulfides in sulfur cathode and achieve high sulfur utilization simultaneously. To address the challenges further, it is a good inspiration to create a ternary hybrid structure such as sulfur/graphene oxide/multiwalled carbon nanotube, in which inter-connected carbon nanotubes can not only improve three-dimensional (3D) electrical conductivity but also help in trapping some of the sulfurs and soluble polysulfides in the gaps of GO layers.

According to the above demands, we first report on a facile method to prepare a ternary sulfur/graphene oxide/multiwalled carbon nanotube (S/GO/MWNT) composite via a simple ultrasonic mixing method followed by heat treatment. To the best of our knowledge, there are few studies on the introduction of GO to build the $3 \mathrm{D}$ sulfur-based architecture. In this work, we combined the one-dimensional MWNT and two-dimensional $\mathrm{GO}$ into three-dimensional $\mathrm{GO} /$ MWNT hybrid, forming a highly conductive network for the electron transport and confining the sulfur. The effect of these structure and property advantages on physical and electrochemical properties of the resulting $\mathrm{S} / \mathrm{GO} / \mathrm{MWNT}$ composite as a cathode for Li-S batteries was investigated. The facile preparation method we used is convenient for controlling the amount and uniform distribution of sulfur. In this unique material architecture of S/GO/MWNT composite, the network interlaced by MWNT and wrinkled GO sheets can not only provide fast electron conduction paths and structural stability but also serve as sponges to physically absorb polysulfides to their wrinkled surface and porous structure. Simultaneously, the functional groups on GO surface afford strong binding sites for trapping polysulfide intermediates by chemical absorption. Thus, the multiple effects of GO and MWNT in the S/GO/MWNT composite can play their roles in promoting the electrochemical performance. Electrochemical results confirm that the S/GO/MWNT composite could deliver excellent rate capability and good cycling stability. 


\section{Experimental}

\section{Material preparation}

A mixture of $3.0 \mathrm{~g}$ aqueous suspension of nano-sulfur (US Research Nanomaterials Inc., 10 wt.\%), $2.5 \mathrm{~g}$ single-layer graphene oxide aqueous suspension (US Research Nanomaterials Inc., 2 wt.\%), and $1.7 \mathrm{~g}$ multiwalled carbon nanotube aqueous suspension (US Research Nanomaterials Inc., 3 wt.\%) was added into $30 \mathrm{~mL}$ deionized water. The mixture was dispersed homogeneously for $2 \mathrm{~h}$ using an ultrasonic homogenizer. The suspension mixture was further dried in a vacuum oven at $60{ }^{\circ} \mathrm{C}$ overnight to remove the solvent, and the precipitate was heat-treated at $150{ }^{\circ} \mathrm{C}$ for $3 \mathrm{~h}$ in a tube furnace in Ar gas to obtain the S/GO/MWNT composite. The sulfur content in the final composite was $65 \%$, which was determined using chemical analysis (CHNS, Vario Micro Cube; Elementar). The preparation of the $\mathrm{S} / \mathrm{GO} / \mathrm{MWNT}$ composite is illustrated in Scheme 1.

\section{Material characterization}

The crystalline phases of the composite were determined by $\mathrm{x}$-ray diffraction (XRD, D8 Discover; Bruker) equipped with $\mathrm{Cu} K \alpha$ radiation. Thermogravimetric analysis (TGA) was performed on a thermoanalyzer (DSC-TGA, SDT Q600; TA Company) under $\mathrm{N}_{2}$ atmosphere from 20 to $500{ }^{\circ} \mathrm{C}$ at $10{ }^{\circ} \mathrm{C} \mathrm{min}{ }^{-1}$. The composite surface morphology was examined by field emission scanning electron microscopy (FE-SEM, Leo-1530; Zeiss). The interior structure of sample was observed using transmission electron microscopy (TEM, CM10; Philips) at $60 \mathrm{kV}$. To elucidate the valences of the elements, x-ray photoelectron spectroscopy (XPS) measurement was performed on a PHI-5400 electron spectrometer with non-monochromatized $\mathrm{Mg} \mathrm{K} \alpha$ x-ray as the excitation source.

\section{Electrochemical measurements}

The electrochemical performance of the S/GO/MWNT composite was investigated using coin-type cells (CR2025). The cell was composed of lithium metal anode and S/GO/MWNT cathode separated by a microporous polypropylene separator soaked in $1 \mathrm{M}$ lithium trifluoromethanesulfonate $\left(\mathrm{LiCF}_{3} \mathrm{SO}_{4}\right)$ in dimethoxy ethane (DME) and 1,3-dioxolane (DOL) $(1: 1 \mathrm{v} / v)$ electrolyte. The composite cathode was prepared by mixing 80 wt.\% S/GO/MWNT composite, 10 wt.\% polyvinylidene fluoride (PVDF) (Kynar, HSV900) as a binder, and 10 wt.\% acetylene black (MTI, 99.5\% purity) conducting agent in 1-methyl-2pyrrolidinone (NMP, Sigma-Aldrich, $\geq 99.5 \%$ purity). The resultant slurry was uniformly spread onto aluminum foil using a doctor blade and dried at $50{ }^{\circ} \mathrm{C}$ for $12 \mathrm{~h}$. The resulting cathode film was used to prepare the cathodes by punching circular disks $1 \mathrm{~cm}$ in diameter. The sulfur loading in each electrode was about $3 \mathrm{mg} \mathrm{cm}{ }^{-2}$. The coin cells were assembled in an $\mathrm{Ar}$ (99.9995\%)-filled glove box (MBraun). In order to soak the separator and the surface of electrodes completely, five to six drops of electrolyte was added in each CR2025 cell. The assembled coin cells were tested galvanostatically on a multichannel battery tester (BTS-5V5mA; Neware) between 1.0 and $3.0 \mathrm{~V}$ versus $\mathrm{Li}^{+} / \mathrm{Li}$ electrode at different current densities. Cyclic voltammetry $(\mathrm{CV})$ was carried out on a $\mathrm{CHI} 660 \mathrm{D}$ electrochemical workstation at a scan rate of $0.25 \mathrm{mV} \mathrm{s}^{-1}$ in the potential range of $1.0-3.0 \mathrm{~V}$ versus $\mathrm{Li}^{+} / \mathrm{Li}$. Applied currents and specific capacities were calculated on the basis of the weight of $\mathrm{S}$ in each cathode.

\section{Results and discussion}

The XRD patterns of sulfur, GO, MWNT, S/GO, and S/ GO/MWNT composites are shown in Fig. 1. One can see that the XRD patterns of $\mathrm{S}$ used in this work to prepare a composite exhibits $F d d d$ orthorhombic structure of elemental sulfur (JCPDS\#08 0247). GO only displays one diffraction peak at $2 \theta=11.6^{\circ}(002)$, corresponding to a d-spacing of approximately $7.96 \AA$ that is due to interlamellar water trapped between hydrophilic graphene oxide sheets [28]. After the incorporation of $\mathrm{S}$ with GO, both the diffraction peaks they belong to and graphitic carbon are found in S/GO composite. It can be seen that although the $\mathrm{S} / \mathrm{GO} / \mathrm{MWNT}$ composite presents sharp peaks of $\mathrm{S}$, their intensities are remarkably reduced. The main characteristic feature of the

Scheme 1 Schematic of the S/ GO/MWNT composite preparation

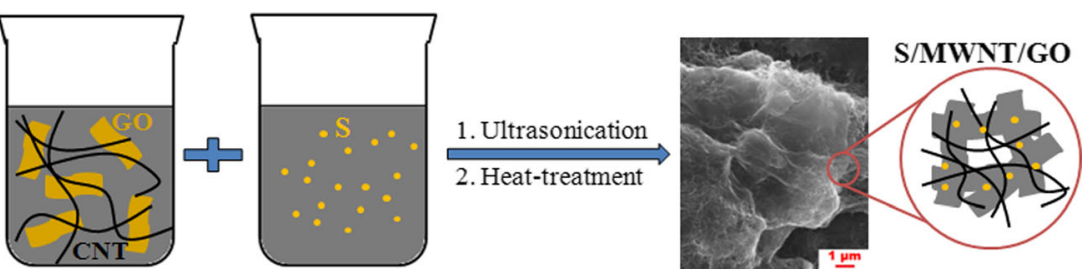


MWNT XRD patterns, corresponding to the (002) plane of graphite [29, 30], is also present in the XRD spectra of the S/GO/MWNT composite at around $26.2^{\circ}$. Beside these, the $\mathrm{S} / \mathrm{GO} / \mathrm{MWNT}$ composite displays a strong diffraction peak at around $11.6^{\circ}$, which can be indexed as the (001) reflection of GO. Furthermore, no peak shift could be observed in the S/GO/MWNT composite, which could be an indication of the absence of phase transformations due to simple ultrasonic mixing, and the sulfur crystal structure remained in the S/GO/MWNT composite. Conversely, the minor peaks of sulfur could not be observed in the composite XRD spectra, which could be likely due to well-dispersed state of nanoscopic sulfur in the GO/MWNT hierarchical 3D structure, as it is discussed further. The sulfur loading contents in the $\mathrm{S} / \mathrm{GO}$ and $\mathrm{S} / \mathrm{GO} / \mathrm{MWNT}$ composites are estimated by TGA under $\mathrm{N}_{2}$ atmosphere, with a heating rate of $10{ }^{\circ} \mathrm{C} \mathrm{min}^{-1}$. As shown in Fig. 1b, all the TGA curves with one-step weight loss are from around 180 to $300{ }^{\circ} \mathrm{C}$, while the composites remain approximately
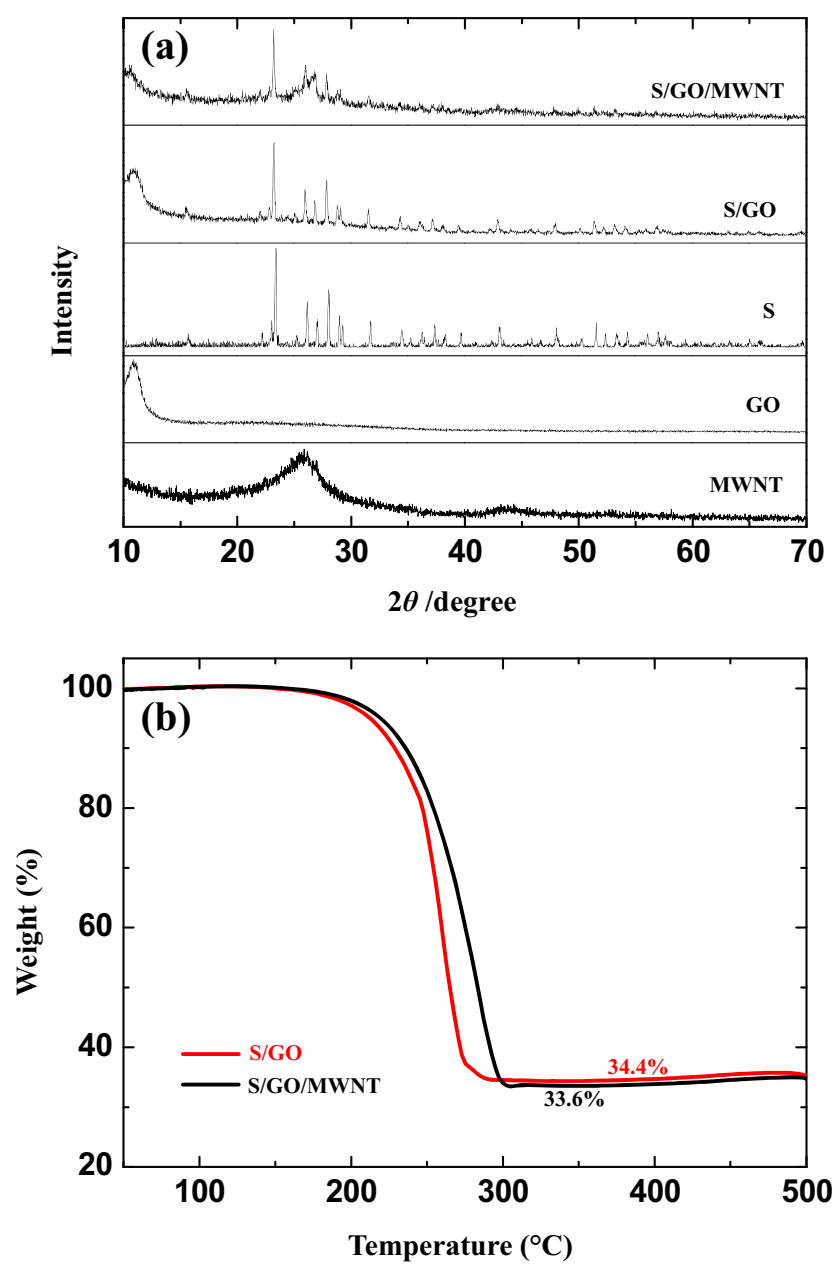

Fig. 1 a XRD patterns of the synthesized samples, $\mathbf{b}$ thermogravimetric curves of $\mathrm{S} / \mathrm{GO}$ and $\mathrm{S} / \mathrm{GO} / \mathrm{MWNT}$ composite unchanged from 300 to $500{ }^{\circ} \mathrm{C}$. The $\mathrm{S} / \mathrm{GO}$ and $\mathrm{S} / \mathrm{GO} /$ MWNT composites show around 65.5 and $66.4 \%$ sulfur content, respectively. The similar amounts of sulfur content in different composites can eliminate the influence of different sulfur content on electrochemical performances.

To investigate the morphology of the obtained S/GO and $\mathrm{S} / \mathrm{GO} / \mathrm{MWNT}$ composites, the SEM images were measured. As shown in Fig. 2a, the GO sheets in $\mathrm{S} /$ GO composite keep their wrinkly surface and sulfur is mainly distributed on the surface of GO sheets. The gaps among GO sheets are bad for transmitting and electrons are hampering the soluble polysulfides. In contrast, Fig. 2b-d exhibits the SEM images of S/GO and S/GO/MWNT composites at different magnifications. The curly MWNT and GO sheets contribute to the hybrid 3D interconnected structure of the S/GO/MWNT composite (Fig. 2a). At a higher magnification in Fig. $2 \mathrm{c}$, it can be seen that the surface of GO layers are smooth, suggesting that the MWNT is mainly filled in the gaps among GO layers, which can improve the ability of electronic transmission. From Fig. 2c, one can see that sulfur and MWNT are well dispersed in the 3D connected structure. There is no agglomeration of bulk sulfur in the S/GO/MWNT composite.

To gain further insight into the morphology, the $\mathrm{S} /$ $\mathrm{GO}$ and $\mathrm{S} / \mathrm{GO} / \mathrm{MWNT}$ composites were studied by means of TEM measurement (Fig. 3) Figure 3a shows the relatively smooth surface of GO sheets after loading sulfur in S/GO composite. The smooth surface is not advantageous for hampering the soluble polysulfides. The TEM image of the S/GO/MWNT composite (Fig. 3b) illustrates a thin/transparent sheet of GO with wrinkled paper-like structure that covers the sulfur/MWNT particles with an interconnected network structure. MWNT can be considered as bridges, effectively connecting GO sheets with reduced interfacial electrical resistance, as shown in Fig. 3c. Figure 3d reveals that MWNT is uniformly embedded in the space framework of GO sheets, which agrees well with the result of the SEM images (Fig. 2b-d), confirming that this facile one-pot method is an effective way of preparing homogeneous conductive sulfur composites. Furthermore, the results show that the presence of MWNT inhibits closer stacking of GO and leads to the formation of a 3D network structure with a loose architecture.

To elucidate the valences of the elements and probe chemical bonding in surface chemistry of the system, XPS measurements were performed (Fig. 4). A full-scan spectrum of S/ GO/MWNT composite is presented in Fig. 4a. As expected, sulfur, oxygen, and carbon are the three main elements of the composite. The C1s spectra, the O1s spectra, and the S2p spectra have respectively revealed the valence states of 0 , 
Fig. 2 SEM images of S/GO (a) and $\mathrm{S} / \mathrm{GO} / \mathrm{MWNT}$ (b-d) composite at various magnifications
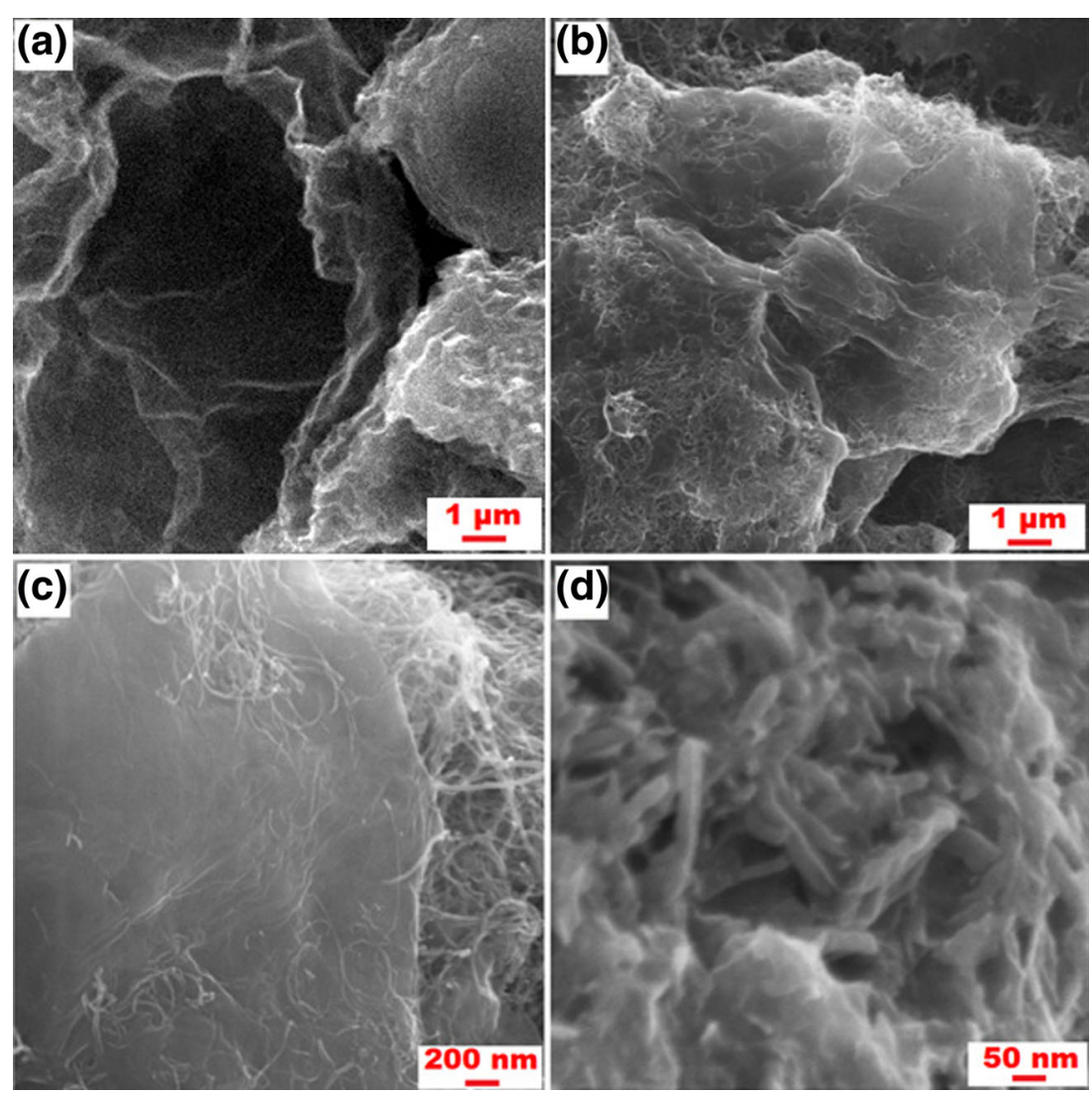

Fig. 3 TEM images of S/GO (a) and S/GO/MWNT (b-d) composite at various magnifications
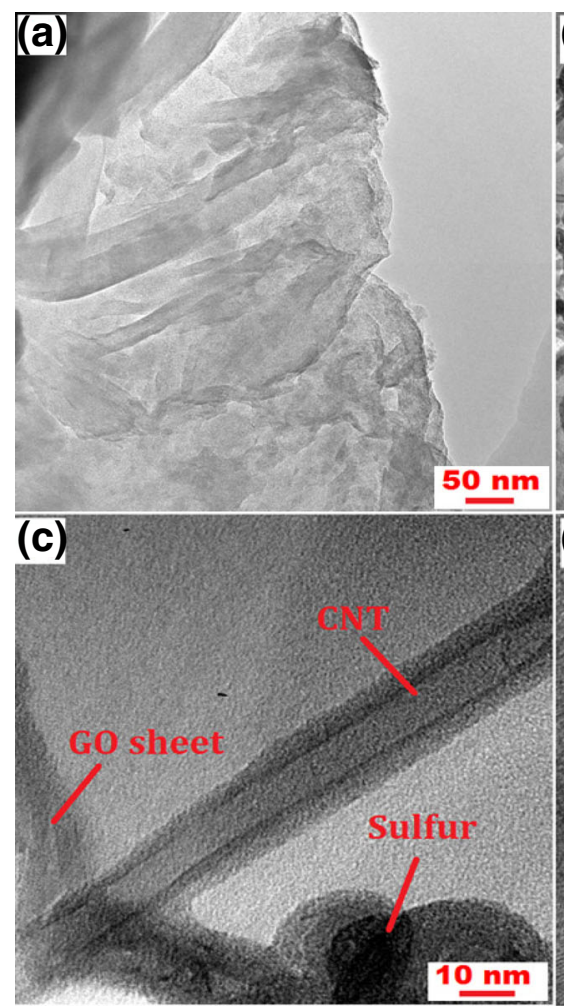

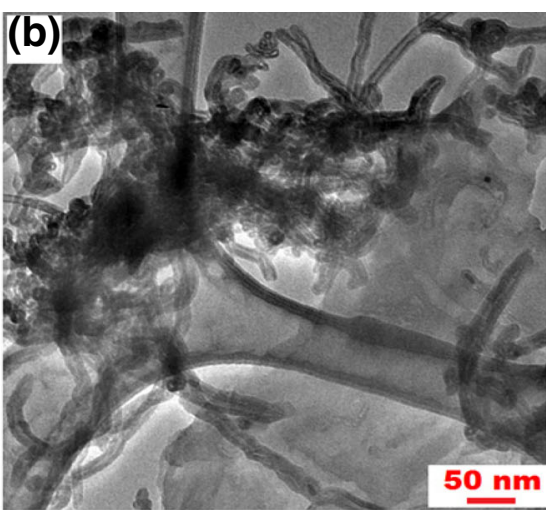

(d) 
-2 , and 0 for $\mathrm{C}, \mathrm{O}$, and $\mathrm{S}$ in $\mathrm{S} / \mathrm{GO} / \mathrm{MWNT}$, respectively (Fig. $4 \mathrm{~b}-\mathrm{d})$. Figure $4 \mathrm{~b}$ exhibits one strong peak at $284.6 \mathrm{eV}$ and weak component peaks at 285.8, 287.1, and $288.6 \mathrm{eV}$, corresponding to carbon species of $\mathrm{C}-\mathrm{O} / \mathrm{C}-\mathrm{S}, \mathrm{C}=\mathrm{O}$, and $\mathrm{O}-\mathrm{C}=\mathrm{O}$, respectively [31]. The $\mathrm{O} 1 \mathrm{~s}$ spectrum of the composite shown in Fig. 4c can be assigned to the formation of $\mathrm{C}=\mathrm{O}, \mathrm{S}-\mathrm{O}$, and $\mathrm{C}-\mathrm{O}$ bonds, according to the peaks at 531.1, 532.2, and $533.3 \mathrm{eV}$, respectively [32]. Figure 4d shows the high resolution core level spectra of S2p in S/GO/MWNT composite. The peaks at 163.6 and $164.8 \mathrm{eV}$ are attributed to $\mathrm{S} 2 \mathrm{p} 3 / 2$ and $\mathrm{S} 2 \mathrm{p} 1 / 2$, respectively [33]. The two peaks are assigned to $\mathrm{S}-$ $\mathrm{S}$ bonds. The peaks at 168.6 and $171.0 \mathrm{eV}$ are assigned to $\mathrm{S}-\mathrm{O}$ and $\mathrm{S}=\mathrm{O}$ bonds [34], indicating a strong bonding of $\mathrm{S}$ and $\mathrm{GO}$ via a simple ultrasonic mixing process followed by heat treatment. This strong adherence of sulfur on GO coating layer through $\mathrm{S}-\mathrm{O}$ bonding have been confirmed in the following electrochemical tests as an effective way of confining the polysulfides' dissolution.

The CV curves of initial three cycles of Li-S cell with $\mathrm{S} / \mathrm{GO} / \mathrm{MWNT}$ composite cathode are shown in Fig. 5a. It can be noticed that all the cathodic $\mathrm{CV}$ data evidence two major stages $\left(2.35\right.$ and $2.05 \mathrm{~V}$ vs. $\mathrm{Li}^{+} / \mathrm{Li}$ ) of the redox processes in the system, which agrees well with the literature data and could be attributed to the transition of $\mathrm{S}$ to polysulfides $\left(\mathrm{Li}_{2} \mathrm{~S}_{8}, \mathrm{Li}_{2} \mathrm{~S}_{6}, \mathrm{Li}_{2} \mathrm{~S}_{4}\right)$ and their further transformation into lithium sulfide $\left(\mathrm{Li}_{2} \mathrm{~S}\right)$, respectively [35]. In the reverse scans, only one sharp anodic peak is observed at about $2.55 \mathrm{~V}$ versus $\mathrm{Li}^{+} / \mathrm{Li}$, which is associated with the reoxidation of the discharged products $\left(\mathrm{Li}_{2} \mathrm{~S}\right.$ and $\mathrm{Li}_{2} \mathrm{~S}_{2}$ ) to $\mathrm{Li}_{2} \mathrm{~S}_{8}$. Furthermore, during the first cycle, the activation process associated with the penetration and transport of the electrolyte and lithium ions through the GO layer on the $\mathrm{S} / \mathrm{GO} / \mathrm{MWNT}$ composite leads to an anodic peak at slightly lower potential. No additional/side reactions were indicated from the $\mathrm{CV}$ data, suggesting good reversibility of the redox processes.

Figure $5 \mathrm{~b}$ depicts the typical initial discharge/charge voltage profiles of the electrodes at $0.1 \mathrm{C}$ rate

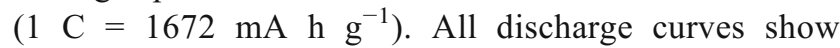
two potential plateaus that are consistent with the peaks in the $\mathrm{CV}$ data and are also well documented in the literature. The S/GO/MWNT composite delivers a high initial discharge capacity of about $1230 \mathrm{~mA} \mathrm{~h} \mathrm{~g}^{-1}$ at $0.1 \mathrm{C}$. At the second cycle, a large reversible capacity of about $1135 \mathrm{~mA} \mathrm{~h} \mathrm{~g}^{-1}$ is preserved, corresponding to about $92.3 \%$ capacity retention. The corresponding coulombic efficiency in the second discharge/charge cycle was about $90.8 \%$. At the third cycle, the $\mathrm{S} / \mathrm{GO} /$ MWNT cathode can still maintain a discharge capacity of about $1100 \mathrm{~mA} \mathrm{~h} \mathrm{~g}^{-1}$, exhibiting a good electrochemical reversibility.

The cyclability and rate performance are important challenging and key aspects of the electrode material
Fig. 4 XPS spectra of $\mathrm{S} / \mathrm{GO} /$ MWNT composite: a full spectra, b C1s spectra, c $\mathrm{O} 1$ spectra, and d S2p spectra
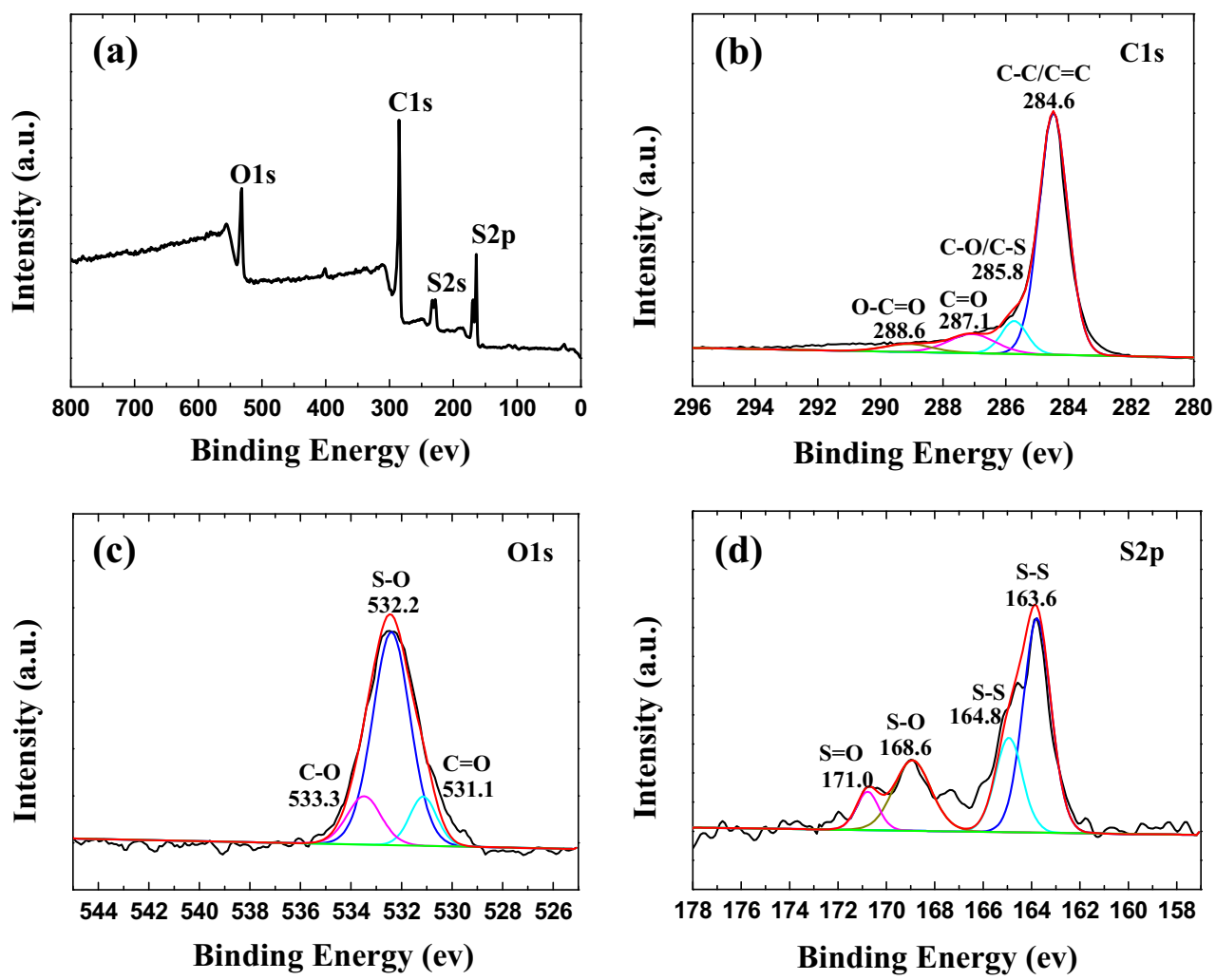

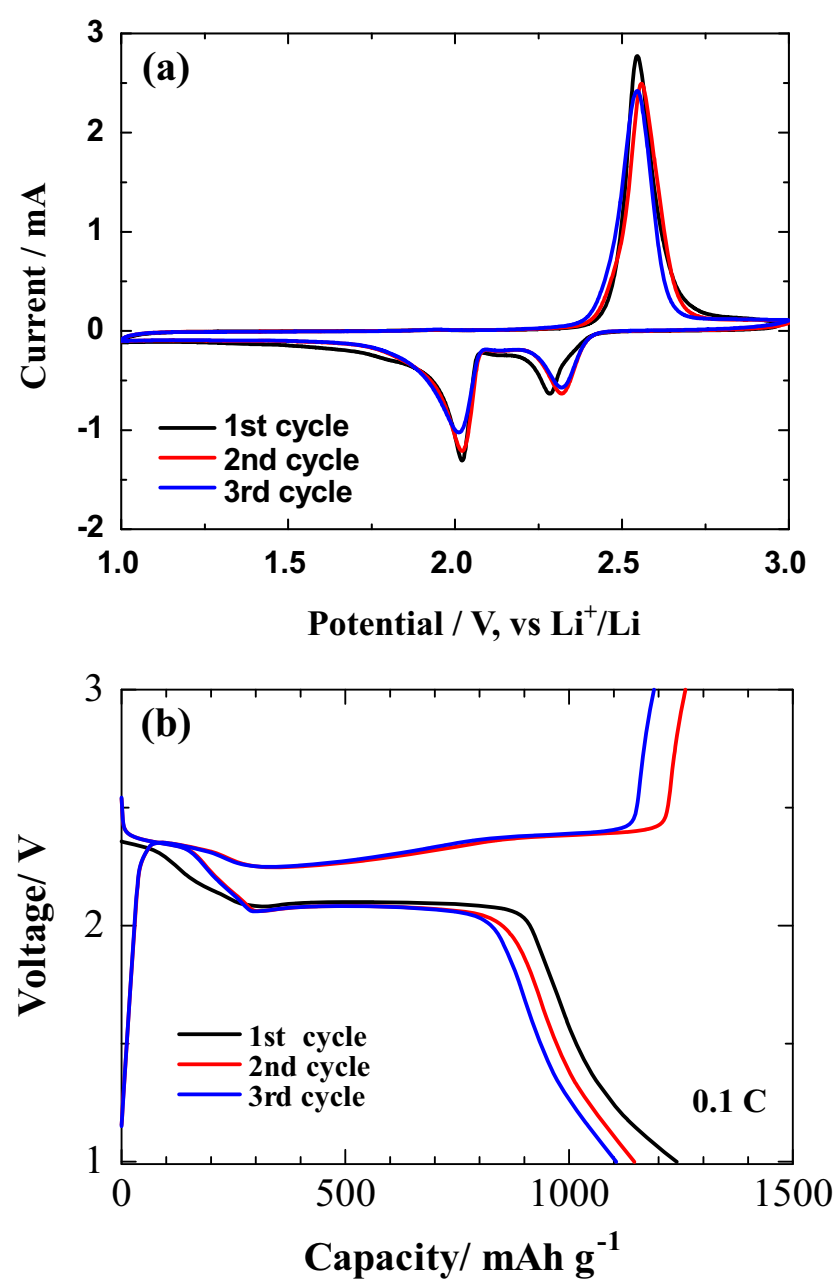

Fig. 5 a $\mathrm{CV}$ curve of the $\mathrm{S} / \mathrm{GO} / \mathrm{WMNT}$ electrode, b charge-discharge profiles of the $\mathrm{S} / \mathrm{GO} / \mathrm{WMNT}$ electrode at $0.1 \mathrm{C}$

characterization. Figure 6a shows cyclabilities of the $\mathrm{S} /$ $\mathrm{GO}$ and $\mathrm{S} / \mathrm{GO} / \mathrm{MWNT}$ composites cathode at $0.1 \mathrm{C}$ in Li-S cells. It can easily be seen from Fig. 6a that both the initial specific capacities and capacity retentions of S/GO/MWNT cathode are much better than those of the $\mathrm{S} / \mathrm{GO}$ cathode. In detail, the $\mathrm{Li}-\mathrm{S}$ cell with $\mathrm{S} / \mathrm{GO} /$ MWNT cathode delivers high initial specific capacity of $1241 \mathrm{~mA} \mathrm{~h} \mathrm{~g}^{-1}$ at $0.1 \mathrm{C}$. The Li-S cell maintains a reversible capacity of $773 \mathrm{~mA} \mathrm{~h} \mathrm{~g}{ }^{-1}$ after 100 cycles, corresponding to about $62.3 \%$ capacity retention. In contrast, the Li-S cell with $\mathrm{S} / \mathrm{GO}$ cathode only delivers the initial specific capacity of $1069 \mathrm{~mA} \mathrm{~h} \mathrm{~g}^{-1}$ and remains the reversible capacity of $405 \mathrm{~mA} \mathrm{~h} \mathrm{~g}^{-1}$ after 100 cycles at $0.1 \mathrm{C}$. The capacity retention of $\mathrm{S} / \mathrm{GO}$ cathode is only $37.9 \%$. Both S/GO and S/GO/MWNT cathodes exhibit a high coulombic efficiency of about $95 \%$ over 100 cycles. It should be noted that the coulombic efficiency of S/GO cathode is a little bit lower in the first several cycles, which could be inferred from the electrode condition. The soluble polysulfides
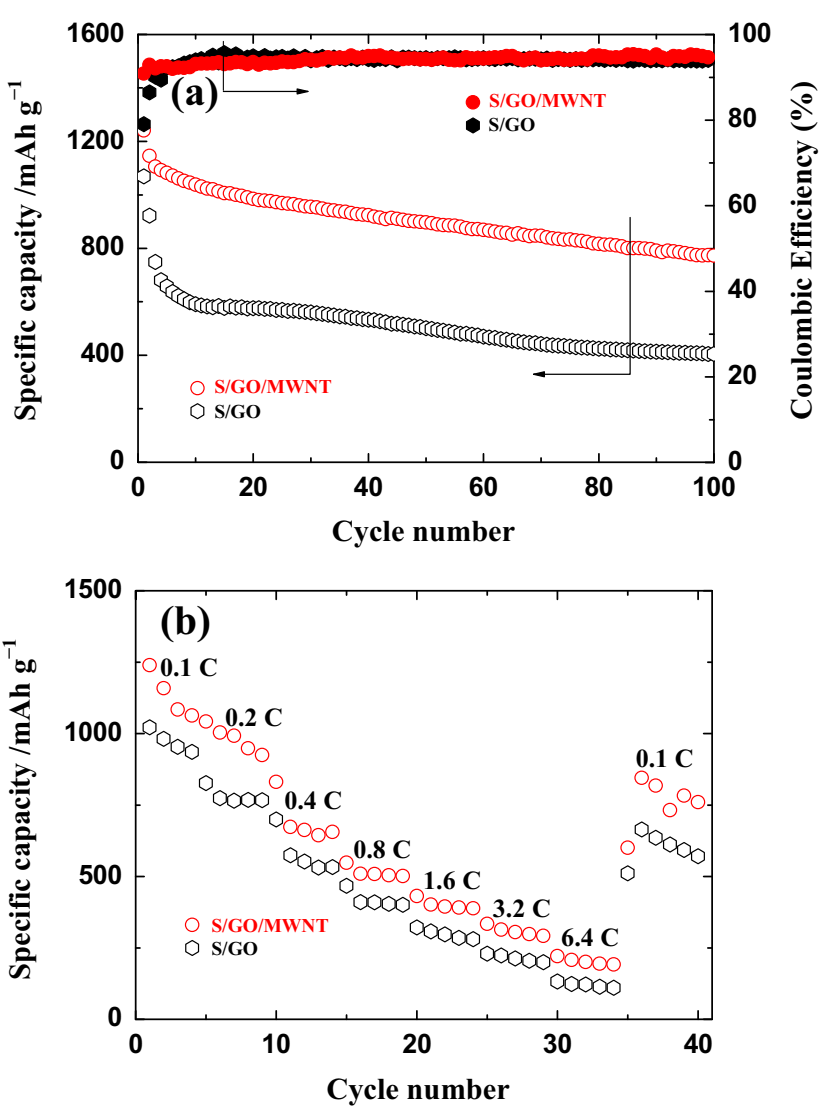

Fig. 6 a Cycle performance at $0.1 \mathrm{C}$ and $\mathbf{b}$ rate performance of the S/GO and $\mathrm{S} / \mathrm{GO} / \mathrm{WMNT}$ electrodes

oxidized from sulfur in the shallow surface zone of the S/GO cathode would dissolve in the electrolytes because there are not enough GO layers to confine and adsorb these soluble polysulfides [13]. Thus, the occurred shuttle mechanism resulted in the faster capacity attenuation and lower coulombic efficiency in the first several cycles. For S/GO/MWNT cathode, the stable coulombic efficiency and enhanced cycle performance could be attributed to the shuttle effect suppression via a strong adherence of sulfur to the flexible three-dimensional conductive matrix combined by GO layers and MWNT.

The rate performances of the $\mathrm{S} / \mathrm{GO}$ and $\mathrm{S} / \mathrm{GO} / \mathrm{MWNT}$ composites were investigated at various charge-discharge rates, and the obtained results are presented in Fig. 6 b. The capacities of the both composites decrease gradually with current density because the active sulfur participating in electrochemical reactions becomes less and less as the current density increases. For $\mathrm{S} / \mathrm{GO} / \mathrm{MWNT}$ composite, the reversible capacities of 1240, 1004, 674, 509, and $401 \mathrm{~mA} \mathrm{~h} \mathrm{~g}^{-1}$ were achieved at current rates of $0.1,0.2,0.4,0.8$, and $1.6 \mathrm{C}$, respectively. An increase in current rate from 3.2 to $6.4 \mathrm{C}$ caused a drop in discharge capacity from about 314 to $208 \mathrm{~mA} \mathrm{~h} \mathrm{~g}^{-1}$. Notwithstanding, the discharge capacity was mostly 

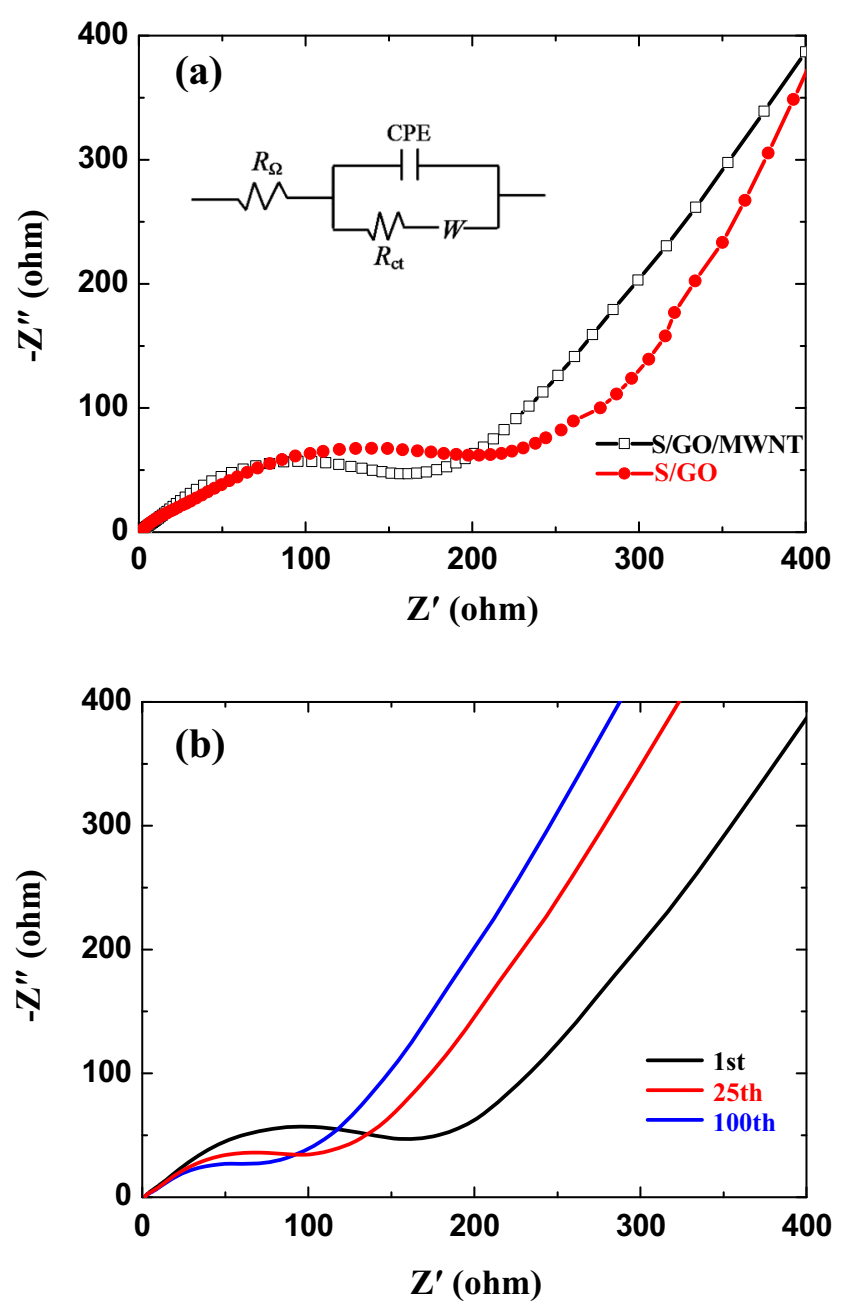

Fig. 7 a Nyquist plots of S/GO/WMNT and S/GO electrodes after one cycle, b Nyquist plots of $\mathrm{S} / \mathrm{GO} / \mathrm{WMNT}$ electrode after different cycles. Insert in Fig. 6a is the fitting equivalent circuit

recovered $\left(845 \mathrm{~mA} \mathrm{~h} \mathrm{~g}^{-1}\right)$ when the cycling rate was switched back to $0.1 \mathrm{C}$. By contrast, the S/GO composite only showed the reversible capacities of 1022, 774, 574, 410,308, 224, and $124 \mathrm{~mA} \mathrm{~h} \mathrm{~g}^{-1}$ at current rates of $0.1,0.2,0.4,0.8$, and $1.6 \mathrm{C}$, respectively. At each current rate, the $\mathrm{S} / \mathrm{GO} / \mathrm{MWNT}$ composite has more reversible capacity of $100-200 \mathrm{~mA} \mathrm{~h} \mathrm{~g}^{-1}$ than that of the $\mathrm{S} / \mathrm{GO}$ composite. This is due to a good electrical conductivity of MWNT as a conductive matrix in the sulfur electrode. Furthermore, the formed three-dimensional hierarchical structure of the $\mathrm{S} / \mathrm{GO} / \mathrm{MWNT}$ composite provides short lithium ion diffusion distance and favorable kinetics, which are important for enhancing the rate capability of electrodes.

In order to analyze the effect of various additives on the conductivity and charge transfer behavior the $\mathrm{S} / \mathrm{GO} /$ MWNT and S/GO electrodes, EIS measurements are performed. The comparative EIS data for the two electrodes measured after the first cycle are shown in Fig. 7a. The EIS spectra of the S/GO/MWNT electrode after different cycles at $0.2 \mathrm{C}$ are shown in Fig. $7 \mathrm{~b}$. Obviously, all the impedance plots are composed of a high-to-medium frequency semicircle and a low frequency straight line, which can be fitted by the equivalent circuit insert in Fig. 7a. The intercept in the high frequency region corresponds to the ohmic resistance $\left(R_{\Omega}\right)$, which combines total resistance of the electrolyte, separator, and electrical contacts [36]. The semicircle in the high middle frequency region is attributed to the constant phase capacitance (CPE) of SEI film and charge transfer reaction $\left(R_{\mathrm{ct}}\right)$. The straight line in low frequency representing the Warburg resistance $(W)$ is assigned to the solid-state diffusion of $\mathrm{Li}^{+}$within the solid active mass.

The AC impedance fitting results for S/GO/WMNT and $\mathrm{S} / \mathrm{GO}$ electrodes are listed in Table 1 . As can be seen in Table 1 , the $R_{\Omega}$ values are almost the same throughout the experiments due to the same electrolyte and fabrication parameters. The $R_{\mathrm{ct}}$ of $\mathrm{S} / \mathrm{GO} / \mathrm{WMNT}$ and S/GO electrodes after one cycle are 161.6 and 204.2 $\Omega$, respectively. The lower CT impedance of the S/GO/MWNT electrode indicates that the MWNT additive plays a significant role in improving the conductivity. The charge transfer enhancement effect by crisscrossed MWNT during the GO sheets in composite could be considered as one of the main reasons of the electrochemical performance enhancement of the $\mathrm{S} / \mathrm{GO} /$ MWNT composite compared with its S/GO counterpart. The CT impedance of the S/GO/MWNT electrode gradually decreases with cycling (Fig. 6b). After the 1st, 25 th, and 100th cycle, the values of $R_{\mathrm{ct}}$ are 77.5, 104.5 , and $161.6 \Omega$, respectively (Table 1 ). This phenomenon could be due to the existence of an activation process and the gradual formation of charge transfer channels in the special structure of the S/GO/MWNT composite as the test proceeded.
Table 1 The AC impedance fitting results for $\mathrm{S} / \mathrm{GO} / \mathrm{WMNT}$ and $\mathrm{S} / \mathrm{GO}$ electrodes

\begin{tabular}{lccll}
\hline & $\begin{array}{l}\text { S/GO after } \\
1 \text { cycle }\end{array}$ & $\begin{array}{l}\mathrm{S} / \text { GO/WMNT after } \\
1 \text { cycle }\end{array}$ & $\begin{array}{l}\mathrm{S} / \mathrm{GO} / \mathrm{WMNT} \text { after } \\
25 \text { cycles }\end{array}$ & $\begin{array}{l}\mathrm{S} / \mathrm{GO} / \mathrm{WMNT} \text { after } \\
100 \text { cycles }\end{array}$ \\
\hline$R_{\Omega}(\Omega)$ & 2.2 & 1.8 & 1.74 & 1.71 \\
$R_{\mathrm{ct}}(\Omega)$ & 204.2 & 161.6 & 104.5 & 77.5 \\
\hline
\end{tabular}




\section{Conclusions}

A sulfur/graphene oxide/multiwalled carbon nanotube (S/GO/ MWNT) composite with three-dimensional hierarchical structure was successfully prepared via a simple ultrasonic mixing of nano-sulfur, GO, and MWNT aqueous suspensions followed by heat treatment. Short duration and low temperature heat treatment allowed the increase of the sulfur content in the cathode material up to $65 \mathrm{wt} . \%$. In S/GO/MWNT composite, the introduction of MWNT can help the interlaced network to provide fast electron conduction paths and structural stability. The introduction of GO layer inhibits the shuttle effect via trapping the polysulfides and minimizes the loss of active mass of sulfur cathode, and consequently contributes to the cycling stability enhancement. At current rates of $0.1,0.2,0.4$, and $0.8 \mathrm{C}$, the $\mathrm{S} / \mathrm{GO} / \mathrm{MWNT}$ cathode shows high reversible capacities of $1240,1004,674$, and $509 \mathrm{~mA} \mathrm{~h} \mathrm{~g}^{-1}$, respectively. After a 100-cycle stability test at $0.1 \mathrm{C}$, the cathode still exhibits stable capacity of $773 \mathrm{~mA} \mathrm{~h} \mathrm{~g}^{-1}$, showing an excellent cycling stability. Furthermore, this study demonstrates that the GO and MWNT combinatively function as a flexible threedimensional conductive matrix, favoring the ion transport and enhanced electrolyte diffusion.

Acknowledgments This research was supported by the National Natural Science Foundation of China (Grant No. 21406052) and financial support by Program for the Outstanding Young Talents of Hebei Province (Grant No. BJ2014010). The support was also from the research grant4649/GF from the Ministry of Education and Science of Kazakhstan.

\section{References}

1. Yuan Z, Peng HJ, Hou TZ, Huang JQ, Chen CM, Wang DW, Cheng XB, Wei F, Zhang Q (2016) Nano Lett 16:519

2. Manthiram A, Chung SH, Zu C (2015) Adv Mater 27:1980

3. Li L, Wu ZP, Sun H, Chen D, Gao J, n Suresh S, Chow P, Singh CV, Koratkar N (2015) ACS Nano 9:11342

4. Manthiram A, Fu YZ, Chung SH, Zu CX, Su YS (2014) Chem Rev 114:11751

5. Moon S, Jung YH, Jung WK, Jung DS, Choi JW, Kim DK (2013) Adv Mater 25:6547

6. Yuan G, Wang G, Wang H, Bai J (2015) J Solid State Electrochem 19:1143

7. Zhang Y, Zhao Y, Yermukhambetova A, Bakenov Z, Chen P (2013) J Mater Chem A 1:295
8. Zhou G, Li L, Ma C, Wang S, Shi Y, Koratkar N, Ren W, Li F, Cheng HM (2015) Nano Energy 11:356

9. Wei P, Fan MQ, Chen HC, Yang XR, Wu HM, Chen JD, Li T, Zeng LW, Li CM, Ju QJ, Chen D, Tian GL, Lv CJ (2016) Renew Energy $86: 148$

10. Kim JH, Fu K, Choi J, Sun S, Kim J, Hu L, Paik U (2015) Chem Commun 51:13682

11. Li J, Li K, Li MQ, Gosselink D, Zhang Y, Chen P (2014) J Power Sources 252:107

12. Zhao Y, Bakenova Z, Zhang Y, Peng H, Xie H, Bakenov Z (2015) Ionics 21:1925

13. Yuan G, Wang G, Wang H, Bai J (2015) J Nanopart Res 17:36

14. Xu B, Yue SF, Sui ZY, Zhang XT, Hou SS, Cao GP, Yang YS (2011) Energy Environ Sci 4:2826

15. Niu SZ, Lv W, Zhang C, Shi Y, Zhao J, Li B, Yang QH, Kang FY (2015) J Power Sources 295:182

16. Wu YS, Xu CM, Guo JX, Su QM, Du GH, Zhang J (2014) Mater Lett 137:277

17. Zhao MQ, Liu XF, Zhang Q, Tian GL, Huang JQ, Zhu WC, Wei F (2012) ACS Nano 6:10759

18. Sun L, Kong WB, Jiang Y, Wu HC, Jiang KL, Wang JP, Fan SS (2015) J Mater Chem A 3:5305

19. Zhu L, Peng HJ, Liang JY, Huang JQ, Chen CM, Guo XF, Zhu WC, Li P, Zhang Q (2014) Nano Energy 11:746

20. Hart CJ, Cuisinier M, Liang X, Kundu D, Garsuch A, Nazar LF (2015) Chem Commun 51:2308

21. Liang Z, Zheng G, Li W, Seh ZW, Yao H, Yan K, Kong D, Cui Y (2014) ACS Nano 8:5249

22. Tao X, Wang J, Ying Z, Cai Q, Zheng G, Gan Y, Huang H, Xia Y, Liang C, Zhang W, Cui Y (2014) Nano Lett 14:5288

23. Liang X, Hart C, Pang Q, Garsuch A, Weiss T, Nazar LF (2015) Nat Commun 6:5682

24. Ji LW, Rao MM, Zheng HM, Zhang L, Li YC, Duan WH, Guo JH, Cairns EJ, Zhang YG (2011) J Am Chem Soc 133:18522

25. Zhou WD, Chen H, Yu YC, Wang DL, Cui ZM, DiSalvo FJ, Abruña HD (2013) ACS Nano 7:8801

26. Sun YQ, Wu Q, Shi GQ (2011) Energy Environ Sci 4:1113

27. Zhang Y, Zhao Y, Bakenov Z (2014) Ionics 20:1047

28. Park SJ, An J, Jung I, Piner RD, An SJ, Li XS, Velamakanni A, Ruoff RS (2009) Nano Lett 9:1593

29. Zhang Y, Zhao Y, Konarov A, Gosselink D, Soboleski HG, Chen P (2013) Solid State Ionics 238:30

30. Pirlot C, Willems I, Fonseca A, Nagy JB, Delhalle J (2002) Adv Eng Mater 4:109

31. Stankovich S, Dikin DA, Piner RD, Kohlhaas KA, Kleinhammes A, Jia YY, Wu Y, Nguyen SBT, Ruoff RS (2007) Carbon 45:1558

32. Zhang L, Ji LW, Glans PA, Zhang YG, Zhu JF, Guo JH (2012) Phys Chem Chem Phys 14:13670

33. Zhou GM, Yin LC, Wang DW, Li L, Pei SF, Gentle IR, Li F, Cheng HM (2013) ACS Nano 7:5367

34. Smart RSC, Skinner WM, Gerson AR (1999) Surf Interface Anal 28:101

35. Yang Y, Yu G, Cha JJ, Wu H, Vosgueritchian M, Yao Y, Bao Z, Cui Y (2011) ACS Nano 5:9187

36. Aurbach D (2003) J Power Sources 119:497 